Original investigation

Open Access

\title{
Changes in body mass index, leptin and adiponectin in Japanese children during a three-year follow-up period: a population-based cohort study
}

\author{
Rimei Nishimura*1,2, Hironari Sano ${ }^{1}$, Toru Matsudaira ${ }^{1}$, Aya Morimoto1, \\ Yumi Miyashita1 ${ }^{1}$, Takako Shirasawa ${ }^{3}$, Akatsuki Kokaze ${ }^{3}$ and Naoko Tajima ${ }^{1}$
}

Address: ${ }^{1}$ Division of Diabetes, Metabolism and Endocrinology, Department of Internal Medicine, Jikei University School of Medicine, Tokyo, Japan, ${ }^{2}$ Graduate School of Public Health, University of Pittsburgh, Pittsburgh, PA, USA and ${ }^{3}$ Department of Public Health, Showa University School of Medicine, Tokyo, Japan

Email: Rimei Nishimura* - rimei@jikei.ac.jp; Hironari Sano - hirosano@jikei.ac.jp; Toru Matsudaira - matsuhei@jikei.ac.jp; Aya Morimoto - aya@jikei.ac.jp; Yumi Miyashita - cdw40060@par.odn.ne.jp; Takako Shirasawa - shirasawa@med.showa-u.ac.jp;

Akatsuki Kokaze - akokaze@med.showa-u.ac.jp; Naoko Tajima - ntajima@jikei.ac.jp

* Corresponding author

Published: 3 June 2009

Cardiovascular Diabetology 2009, 8:30 doi:10.1 186/1475-2840-8-30

This article is available from: http://www.cardiab.com/content/8/I/30

(C) 2009 Nishimura et al; licensee BioMed Central Ltd.

This is an Open Access article distributed under the terms of the Creative Commons Attribution License (http://creativecommons.org/licenses/by/2.0), which permits unrestricted use, distribution, and reproduction in any medium, provided the original work is properly cited.
Received: 22 January 2009

Accepted: 3 June 2009

\begin{abstract}
Objective: The study examined changes in and relationship between body mass index (BMI), leptin and adiponectin levels over a 3-year period in a pediatric population-based cohort.
\end{abstract}

Study design: A 3-year prospective cohort study of 268 boys and 25I girls aged 9-10 in Ina, Saitama, Japan.

Results: Median body mass index (BMI) significantly increased from baseline (age 9-I0) to follow up (age I2-13) in boys from 17.1 to $18.3 \mathrm{~kg} / \mathrm{m}^{2}(P<0.00 \mathrm{I})$ and in girls from 16.5 to $18.5 \mathrm{~kg} / \mathrm{m}^{2}(P$ $<0.00 \mathrm{I})$, respectively. Adiponectin values significantly decreased from baseline to follow up in boys ( I 3.5 to $8.9 \mu \mathrm{g} / \mathrm{ml}$, respectively) $(P<0.00 \mathrm{I})$ and in girls $(I 2.4$ to $9.5 \mu \mathrm{g} / \mathrm{ml}$, respectively $)(P<0.00 \mathrm{I})$. Leptin values at follow up significantly decreased from baseline in boys (4.9 to $2.3 \mathrm{ng} / \mathrm{dl}$, respectively) $(P<0.00 \mathrm{I})$ and also in girls $(5.3$ to $5 . \mathrm{l} \mathrm{ng} / \mathrm{dl}$, respectively $)(P=0.049)$.

A relatively strong correlation was seen in BMI (Spearman's correlation coefficient, $r=0.864, P<$ $0.00 \mathrm{I}$ in boys; $r=0.873, P<0.00 \mathrm{I}$ in girls), adiponectin $(r=0.705, P<0.00 \mathrm{I}$ in boys; $r=0.695, P<$ $0.00 \mathrm{I}$ in girls), and leptin ( $r=0.449, P<0.00 \mathrm{I}$ in boys; $r=0.610, P<0.00 \mathrm{I}$ in girls) before and after the three-year period.

The ratio of follow up to baseline BMI was negatively correlated with that for adiponectin $(r=$ $0.224, P<0.00 \mathrm{I}$ in boys; $r=-0.165, P=0.00 \mathrm{I}$ in girls) and positively correlated with that for leptin ( $r=0.518, P<0.001$ in boys; $r=0.609, P<0.001$ in girls).

Conclusion: This study demonstrated that baseline adiponectin, leptin and BMI values measured at ages 9-10 correlated with those measured three years later. However, adiponectin values decreased and leptin values increased in those subjects whose BMI increased during over this period. 


\section{Introduction}

The prevalence of pediatric obesity is rising sharply throughout the world, with marked increases also seen in Asia, including Japan [1-3]. While some studies have shown childhood obesity to be a risk factor for the development of adult obesity [4-6] as has low birth weight [7]. Another study has reported that less than half of the pediatric obese cases go on to become obese adults [8]. Therefore there is no clear consensus to the role of pediatric obesity in the development of adult obesity and no clear answers to questions such as what is the age of onset of pediatric obesity that leads to adult cardiovascular disease (CAD), and when intervention should be in initiated in obese children in order to prevent CAD.

Whitaker RC et al. [4] reported that the risk of childhood obesity progressing to adult obesity rises markedly after the age of 10. In Finland, an intervention study was conducted in which the intake of lipids was restricted, beginning at 7 months after birth. Results of this study demonstrated a significant difference in the incidence of obesity between the control and intervention groups after the age of $8[9,10]$. Another report has demonstrated that adult CAD patients tended to have low birth weight, with a lower-than-average BMI up to age 2, with a subsequent sharp increase in body weight before age 11, with the authors citing this growth pattern as a risk factor [7].

In our study, we focused on the 3-year-period corresponding to the ages during which the onset of obesity is most likely to lead to either adult obesity or $\operatorname{CAD}[4,7,10]$. Within a specific region we were able to target almost all the children in this age group, studying changes in their body mass index (BMI), adiponectin and leptin levels, as well as the relationship between these values during the 3year period to investigate any correlation between changes in these parameters and the development of obesity.

\section{Methods}

This study was conducted as part of a pediatric health promotion program [11-14] initiated in 1994 in Ina, Saitama Prefecture, Japan. Ina is approximately $30 \mathrm{~km}$ to the north of Tokyo with a population of 35,000 comprising both farmers and residents who commute to work in Tokyo. In addition to annual national health checkups performed in accordance with the School Health Law, Ina has a unique health-promotion program in place. Of the fourth and seventh graders who had undergone regular health checkups, those who volunteered to take part in the program underwent blood and physical examinations.

The subjects of this study were children aged 9-10 who, in September 1999 or 2000, were all in the fourth grade in 3 elementary schools in town, and who agreed to participate in the study. A total of 304 boys and 282 girls took part in the study's initial survey (100\% registration rate). A follow-up survey was conducted when the subjects reached the seventh grade (ages 12-13).

At the time of the initial and follow-up surveys, the subjects underwent blood tests including leptin and adiponectin measurements and physical measurements that included height and weight.

Adiponectin was measured in accordance with a report by Arita et al using commercially available ELISA kits (Otsuka Pharmaceutical Co., Ltd., Japan) with intra- and inter-assay coefficients of variation below 10\% [15]. Leptin was measured using commercially available RIA kits (Linco Research Inc.) with intra- and inter-assay coefficients of variation below $10 \%$ [16]. BMI was used as an index for obesity status.

All values were expressed as median and interquartile range (IQR). The Kruskal-Wallis test was used to evaluate statistical significance.

Baseline values for each of the variables examined (leptin, adiponectin and BMI) were recorded when the subjects were 9-10 years old. These values were again measured three years later when the children were aged 12-13 (see Table 1). The ratio of the baseline compared to follow-up values were examined for each test variable. Spearman's correlation coefficient was used to evaluate any correlation between these values. Statistical analyses were made using the SPSS program.

Table I: The median (interquartile range) for body mass index (BMI), adiponectin $(\mu \mathrm{g} / \mathrm{ml})$ and leptin (ng/dI) in the study participants at ages $9-10$ and $12-13$

\begin{tabular}{|c|c|c|c|c|c|c|}
\hline \multirow{2}{*}{$\begin{array}{l}\text { Age group } \\
\text { (n) }\end{array}$} & \multicolumn{3}{|l|}{ 9-10-year-old } & \multicolumn{3}{|l|}{ 12-13-year-old } \\
\hline & Boys (268) & Girls (25I) & Total (519) & Boys & Girls & Total \\
\hline $\mathrm{BMI}\left(\mathrm{kg} / \mathrm{m}^{2}\right)$ & $17.1(15.7-18.7)$ & $16.5(15.2-18.3)$ & $16.7(15.4-18.7)$ & $18.3 * *(16.9-19.8)$ & $18.5^{* *}(17.0-20.3)$ & $18.4 * *(17.0-20.1)$ \\
\hline Adiponectin $(\mu \mathrm{g} / \mathrm{ml})$ & $13.5(9.6-18.2)$ & $12.4(9.5-16.5)$ & $12.9(9.6-17.5)$ & $8.9 * *(6.9-11.3)$ & $9.5^{* *}(7.4-11.8)$ & $9.3^{* *}(7.2-11.6)$ \\
\hline Leptin (ng/dl) & $4.9(3.2-7.8)$ & $5.3(3.8-9.2)$ & $5.0(3.5-8.5)$ & $2.3^{* *}(1.6-3.6)$ & $5.1 *(3.6-7.9)$ & $3.5 * *(2.1-6.0)$ \\
\hline
\end{tabular}

$* P<0.05, * * P<0.001$, vs. values measured at ages $9-10$ years 
The study protocol was approved by two independent institutional review boards (IRB) at Jikei University School of Medicine and Showa University School of Medicine. Written informed consent was obtained from all study participants and their guardians.

\section{Results}

Follow-up rates

Of the 586 children, follow-up physical and laboratory examination was performed on 519 subjects three years later (follow-up rate, $88.6 \%$ ). Relocation was the major reasons that children were lost to follow-up. There was no statistical difference in baseline values between those available for follow-up and those lost to follow-up in gen$\operatorname{der}(P=0.512)$ and BMI $(P=0.958)$.

\section{Values measured at ages 9-10 and at ages I2-13}

Body mass index (BMI) was significantly increased and adiponectin and leptin significantly decreased among study participants for both genders before and after the three-year follow-up. The mean baseline BMI value (kg/ $\left.\mathrm{m}^{2}\right)$ for boys was $17.1(15.7-18.7)$ increasing to 18.3 (16.9-19.8) at follow up $(P<0.001)$, and 16.5 (15.2$18.3)$ increasing to $18.5(17.0-20.3)$ in girls $(P<0.001)$ respectively. The mean baseline adiponectin value $(\mu \mathrm{g} /$ $\mathrm{ml}$ ) in boys dropped from 13.5 (9.6-18.2) to 8.9 (6.911.3) at follow up $(P<0.001)$, and dropped from 12.4 $(9.5-16.5)$ to $9.5(7.4-11.8)$ in girls $(P<0.001)$ respectively. The mean baseline leptin value $(\mathrm{ng} / \mathrm{dl})$ dropped from $4.9(3.2-7.8)$ to $2.3(1.6-3.6)$ in boys $(P<0.001)$ compared to a respective drop from $5.3(3.8-9.2)$ to 5.1 (3.6-7.9) in girls $(P=0.049)$.

\section{Correlation analysis}

Baseline BMI, adiponectin and leptin values measured at ages 9-10 years demonstrated a significant positive correlation with those measured three year later at follow up: BMI (boys, $r=0.864, P<0.001$; girls, $r=0.873, P<$ 0.001 ); adiponectin (boys, $r=0.705, P<0.001$; girls, $r=$ $0.695, P<0.001$ ), and leptin (boys, $r=0.449, P<0.001$; girls, $r=0.610, P<0.001$ ) (Figure 1 ).

A negative correlation was found for the ratios of follow up to baseline adiponectin with that for BMI in both males and females (boys, $r=-0.224, P<0.001$; girls, $r=$ $0.165, P=0.001)$. In contrast a positively correlation was reported for the follow up to baseline leptin ratio with that for BMI in both sexes (boys, $r=0.518, P<0.001$; girls, $r=0.609, P<0.001$ ) (Figure 2).

\section{Discussion}

It is generally believed that obese children will progress to become obese adults [4-7] with reports demonstrating that the greater the age at which a child is obese, the greater the link to adult obesity $[4,5,17,18]$. In addition, the risk of child obesity progressing to adult obesity increases especially after the age of 10 [4]. Thus, in this study, we focused on the 3-year period between the ages of 9-10 and 12-13 representing the greatest risk group and investigated changes in BMI, leptin, and adiponectin.
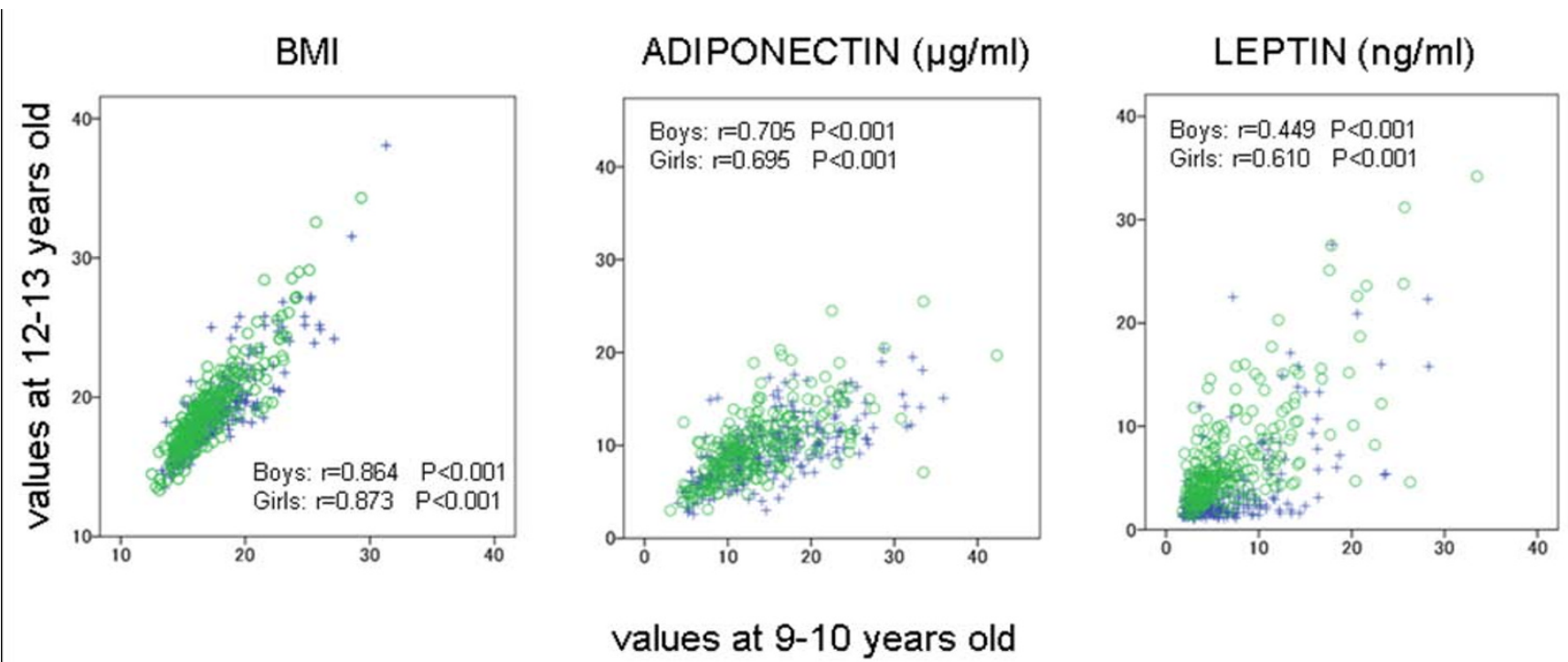

Figure I

Correlation in BMI, adiponectin and leptin between their values at ages $9-10$ and their values measured at 12 - I 3 by gender in the 519 children living in the town of Ina. Boys (+): $n=268$ Girls (O): $n=25$ I. $r$ : Spearman's rank correlation coefficients. 

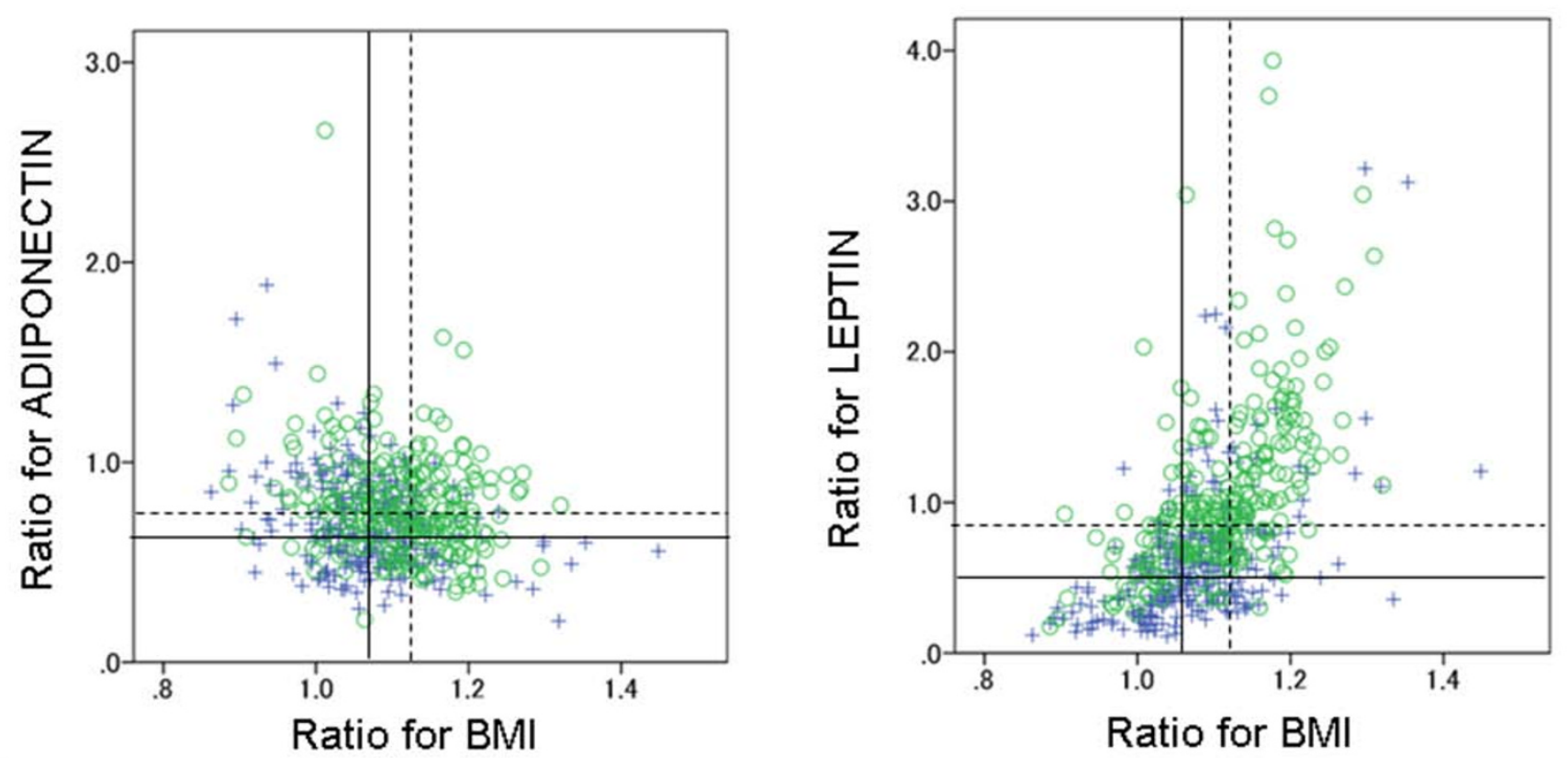

Figure 2

Ratio of the values for BMI, adiponectin and leptin measured at ages $9-10$ to those measured at I2 - I3, and their correlation by gender in the 519 children living in the town of Ina. Boys $(+): n=268, G i r l s(\bigcirc): n=25 I$. $r$ : Spearmans' correlation coefficients. Ratio: values measured at ages 12-13/values measured at ages 9-10. Straight line, medians for boys; dotted line, medians for girls. Adiponectin: $r=-0.224, P<0.001$ in boys, $r=-0.165, P=0.00 \mathrm{I}$ in girls. Leptin: $r=$ $0.518, P<0.001$ in boys, $r=0.609, P<0.001$ in girls.

This study targeted all eligible children living in a typical Japanese town with little population movement. This study was distinctive in that it prospectively followed changes in adipokines in a childhood population-based cohort over a 3-year period. The study results demonstrated that adiponectin, leptin and BMI values measured at baseline (9-10 years) correlated with those measured three years later. Therefore, these three variables measured at ages 9-10 were predictive for results obtained three years later, suggesting that in this age group these variables were likely to be genetically determined. However, adiponectin values were relatively decreased and leptin values relatively increased in children whose BMI increased during the 3-year period. Of note, Cambuli VM et al. reported that adiponectin and leptin were positive metabolic outcome markers following lifestyle intervention in overweight and obese children [19].

The current study showed that adiponectin values measured at ages 12-13 were lower than at ages 9-10. Similar findings have been reported in Germany and in USA, showing that adiponectin values in post-pubertal children are lower than in pre-pubertal children, especially in boys, which is explained by the elevated serum androgen levels in the former $[20,21]$. Other reports of age-related effects on adiponectin show that the adiponectin value drops in a 2-year-old to a greater extent than in a 1-year-old [22], and that the adiponectin values do not change in women aged 18 to 80 [23].

This study also demonstrated that the leptin values at ages 12-13 were lower than those at ages 9-10, especially in boys. Leptin values, which correlate with the amount of body fat present, are reported to increase in girls and decrease in boys after Tanner stage 2 as the pubertal developments proceeds [24]. Another study conducted in 2- to 5-year-old Tsimané children showed that the correlation between body fat and leptin increases markedly with advancing age in females [25]. The lower levels of leptin in boys may partly be explained by the suppressive effect of androgens in the boys [24]. However, our study showed no age-related increase in leptin values in girls.

The current study examined changes in BMI and adipocytokines in Japanese children. Differences in adipocytokines between ethnic groups have been demonstrated in previous reports in the literature $[26,27]$. Therefore, these ethnic differences should be taken into account when the results of this study are used for international comparisons. 
Limitations of this study include the lack of confirmation of pubertal stage (Tanner's stages) of all subjects, as this would have been useful to correlate with the data obtained; this was an observational study covering a specific 3-year period and therefore the values obtained for the metabolic markers may not necessarily be linked directly to adult obesity. This study examined the relationship between the changes in test variables and obesity, and did not take the subjects' lifestyles into consideration. Therefore, evaluation of lifestyle factors is an issue that needs to be addressed in the future.

In conclusion we demonstrated in a Japanese populationbased childhood cohort that baseline adiponectin, leptin and BMI values measured at ages 9-10 correlated with those measured three years later. In addition, those children with an increase in BMI over this period were also found to have decreased adiponectin and increased leptin values. These results suggest that lifestyle intervention in obese children should be initiated between ages 9 and 12 .

It is hoped that continued follow-up of the study participants will help identify potential methods of preventing the onset of visceral obesity and CAD in adulthood.

\section{Competing interests}

The authors declare that they have no competing interests.

\section{Authors' contributions}

RN and NT participated in the design of the study and performed the statistical analyses. HS, TM, AM, YM, TS, and AK participated in the coordination of the study. RN helped to draft the manuscript. All authors have read and approved the final manuscript.

\section{Acknowledgements}

We are indebted to all study participants and their parents. The authors would like to thank all the members of the Board of Education in Ina, Saitama Prefecture, Ina Conference for the Promotion and Implementation of the Childhood Lifestyle-Related Diseases Prevention Examination (Chairman, Yoshihito Toriyama), Michio Sato, Akira Kanda, Eiko Takahashi and Takeshi Kawaguchi.

This study was supported by a grant from the Ministry of Education, Culture, Sports, Science and Technology, Japan (Basic Research [A2] \#|4207020, 2002-2004 and Basic Research [A] \#17209024, 2005-2007). The Ministry of Education, Culture, Sports, Science and Technology, Japan had no direct input into the design or conduct of the study; collection, management, analysis, or interpretation of the data; or preparation, review, or approval of the manuscript.

\section{References}

I. Shirai K, Shinomiya M, Saito Y, Umezono T, Takahashi K, Yoshida S: Incidence of childhood obesity over the last 10 years in Japan. Diabetes Res Clin Pract 1990, I O(Suppl I):S65-70.

2. Deckelbaum RJ, Williams CL: Childhood obesity: the health issue. Obes Res 200I, 9(Suppl 4):239S-243S.

3. Strauss RS, Pollock HA: Epidemic increase in childhood overweight, I 986-I 998. JAMA 200I, 286:2845-2848.
4. Whitaker RC, Wright JA, Pepe MS, Seidel KD, Dietz WH: Predicting obesity in young adulthood from childhood and parental obesity. N Engl J Med 1997, 337:869-73.

5. DiPietro L, Mossberg HO, Stunkard AJ: A 40-year history of overweight children in Stockholm: life-time overweight, morbidity, and mortality. Int J Obes Relat Metab Disord I994, I 8:585-90.

6. Gunnell DJ, Frankel SJ, Nanchahal K, Peters TJ, Davey Smith G: Childhood obesity and adult cardiovascular mortality: a 57-y follow-up study based on the Boyd Orr cohort. Am J Clin Nutr 1998, 67: IIII-8.

7. Barker DJ, Osmond C, Forsen TJ, Kajantie E, Eriksson JG: Trajectories of growth among children who have coronary events as adults. N Engl J Med 2005, 353: I802-9.

8. Kotani K, Nishida M, Yamashita S, Funahashi T, Fujioka S, Tokunaga K, Ishikawa K, Tarui S, Matsuzawa Y: Two decades of annual medical examinations in Japanese obese children: do obese children grow into obese adults? Int J Obes Relat Metab Disord I997, 21:912-2I.

9. Rask-Nissila L, Jokinen E, Terho P, Tammi A, Lapinleimu H, Ronnemaa T, Viikari J, Seppanen R, Korhonen T, Tuominen J, Valimaki I, Simell $O$ : Neurological development of 5 -year-old children receiving a low-saturated fat, low-cholesterol diet since infancy: A randomized controlled trial. JAMA 2000, 284:993-1000.

10. Hakanen M, Lagstrom H, Kaitosaari T, Niinikoski H, Nanto-Salonen K, Jokinen E, Sillanmaki L, Viikari J, Ronnemaa T, Simell O: Development of overweight in an atherosclerosis prevention trial starting in early childhood. The STRIP study. Int J Obes Int J Obes (Lond). 2006 Apr;30(4):618-26 2006, 30(4):618-626.

II. Kanda A, Kamiyama Y, Kawaguchi T: Association of reduction in parental overweight with reduction in children's overweight with a 3-year follow-up. Prev Med 2004, 39:369-72.

12. Kanda A, Watanabe $Y$, Kawaguchi $T$ : Estimation of obesity in schoolchildren by measuring skinfold thickness. Public Health 1997, I I I:29-32.

13. Nishimura R, Kanda A, Sano H, Matsudaira T, Miyashita Y, Morimoto A, Shirasawa T, Kawaguchi T, Tajima N: Glycated albumin is low in obese, non-diabetic children. Diabetes Res Clin Pract 2006, 71:334-8.

14. Nishimura R, Sano H, Matsudaira T, Miyashita Y, Morimoto A, Shirasawa T, Takahashi E, Kawaguchi T, Tajima N: Childhood obesity and its relation to serum adiponectin and leptin: $A$ report from a population-based study. Diabetes Res Clin Pract 2007, 76:245-50.

15. Arita Y, Kihara S, Ouchi N, Takahashi M, Maeda K, Miyagawa J, Hotta K, Shimomura I, Nakamura T, Miyaoka K, Kuriyama H, Nishida M, Yamashita S, Okubo K, Matsubara K, Muraguchi M, Ohmoto Y, Funahashi T, Matsuzawa Y: Paradoxical decrease of an adipose-specific protein, adiponectin, in obesity. Biochem Biophys Res Commun 1999, 257:79-83.

16. Ma Z, Gingerich RL, Santiago JV, Klein S, Smith CH, Landt M: Radioimmunoassay of leptin in human plasma. Clin Chem 1996, 42:942-6.

17. Power C, Moynihan C: Social class and changes in weight-forheight between childhood and early adulthood. Int J Obes 1988, I 2:445-53.

18. Wright CM, Parker L, Lamont D, Craft AW: Implications of childhood obesity for adult health: findings from thousand families cohort study. BMJ 200I, 323:I280-4.

19. Cambuli VM, Musiu MC, Incani M, Paderi M, Serpe R, Marras V, Cossu E, Cavallo MG, Mariotti S, Loche S, Baroni MG: Assessment of adiponectin and leptin as biomarkers of positive metabolic outcomes after lifestyle intervention in overweight and obese children. J Clin Endocrinol Metab 2008, 93:305I-7.

20. Woo JG, Dolan LM, Daniels SR, Goodman E, Martin LJ: Adolescent sex differences in adiponectin are conditional on pubertal development and adiposity. Obes Res 2005, I3:2095-I0I.

21. Bottner A, Kratzsch J, Muller G, Kapellen TM, Bluher S, Keller E, Bluher $M$, Kiess W: Gender differences of adiponectin levels develop during the progression of puberty and are related to serum androgen levels. J Clin Endocrinol Metab 2004, 89:4053-6I.

22. Iniguez G, Soto N, Avila A, Salazar T, Ong K, Dunger D, Mericq V: Adiponectin levels in the first two years of life in a prospective cohort: relations with weight gain, leptin levels and insulin sensitivity. J Clin Endocrinol Metab 2004, 89:5500-3.

23. Ryan AS, Berman DM, Nicklas BJ, Sinha M, Gingerich RL, Meneilly GS, Egan JM, Elahi D: Plasma adiponectin and leptin levels, body 
composition, and glucose utilization in adult women with wide ranges of age and obesity. Diabetes Care 2003, 26:2383-8.

24. Blum WF, Englaro P, Hanitsch S, Juul A, Hertel NT, Müller J, Skakkebaek NE, Heiman ML, Birkett M, Attanasio AM, Kiess W, Rascher W: Plasma leptin levels in healthy children and adolescents: dependence on body mass index, body fat mass, gender, pubertal stage, and testosterone. J Clin Endocrinol Metab 1997, 82:2904- 10.

25. Sharrock KC, Kuzawa CW, Leonard WR, Tanner S, Reyes-García VE, Vadez V, Huanca T, McDade TW: Developmental changes in the relationship between leptin and adiposity among Tsimané children and adolescents. Am J Hum Biol 2008, 20:392-8.

26. van Vliet M, von Rosenstiel IA, Schindhelm RK, Brandjes DP, Beijnen $\mathrm{JH}$, Diamant M: Ethnic differences in cardiometabolic risk profile in an overweight/obese paediatric cohort in the Netherlands: a cross-sectional study. Cardiovasc Diabetol 2009, 8:2.

27. Valsamakis G, Chetty R, McTernan PG, Al-Daghri NM, Barnett AH Kumar $S$ : Fasting serum adiponectin concentration is reduced in Indo-Asian subjects and is related to HDL cholesterol. Diabetes Obes Metab 2003, 5:131-5.

Publish with Bio Med Central and every scientist can read your work free of charge

"BioMed Central will be the most significant development for disseminating the results of biomedical research in our lifetime. "

Sir Paul Nurse, Cancer Research UK

Your research papers will be:

- available free of charge to the entire biomedical community

- peer reviewed and published immediately upon acceptance

- cited in PubMed and archived on PubMed Central

- yours - you keep the copyright 